\title{
Changes in Subjective Well-Being Over Time: Economic and Social Resources do Matter
}

\author{
A. I. Moro-Egido ${ }^{1} \cdot$ M. Navarro² $\cdot$ A. Sánchez ${ }^{2}$
}

Accepted: 1 November 2021 / Published online: 4 December 2021

(c) The Author(s) 2021

\begin{abstract}
This article analyzes the main determinants of changes in subjective well-being over time in Germany distinguishing between long-term and short-term changes. Our findings for the long term indicate that social capital and values and cultural dimensions have the greatest capacity to predict changes in subjective well-being. Likewise, the correlation between economic resources and subjective well-being is weaker due to the small increase registered in household income and because people compare their income with those who are better off and feel envy. In the short term, economic resources have the highest capacity to predict both improvements (ups) and declines (downs) in subjective well-being. Finally, we also suggest that, whenever information is available, personality traits should be taken into account in the analysis of changes in subjective well-being over time in order to achieve more reliable estimates.
\end{abstract}

Keywords Changes in subjective well-being $\cdot$ Economic resources $\cdot$ Social resources . Psychological capital · Public policy

JEL Classification C23 $\cdot$ D60 $\cdot$ I31 $\cdot$ I38

\section{Introduction}

The growing interest among economists in the study of subjective well-being and its determinants stems from the fact that indicators of subjective well-being provide information on non-material aspects of people's well-being, which might affect their economic behaviour (Frey \& Stutzer, 2017; Stutzer \& Frey, 2010). More specifically, the subjective well-being

M. Navarro

marianh@ugr.es

A. 1. Moro-Egido

aimoro@ugr.es

A. Sánchez

sancheza@ugr.es

1 Dpto. Teoría e Historia Económica, Universidad de Granada, C/Campus Cartuja s/n, 18011 Granada, Spain

2 Dpto. Economía Aplicada, Universidad de Granada, C/Campus Cartuja s/n, 18011 Granada, Spain 
approach provides new ways and tools to empirically analyse individual utility and social welfare, as well as for the design and evaluation of public policies (Frey \& Stutzer, 2002; OECD, 2013; Stiglitz et al., 2011). The key idea supporting this approach is that improvements in subjective well-being are positive for both individuals (e.g. better health and productivity) and society as a whole by promoting greater economic growth and social welfare (DiMaria et al., 2019; Oswald et al., 2015; Piekalkiewicz, 2017). In this framework, it is of relevance to properly understand how subjective well-being can be improved or at least maintained for future generations (Rojas, 2016; Stiglitz et al., 2011).

In the social sciences, especially in economics, it is of interest to study changes or temporal variations in variables because they reflect the behavioural patterns of the agents analysed. In this paper, we examine the association between people's subjective well-being and changes or variations in variables of their environment, thus enriching the analysis. In this line, Easterlin (2021) argues in a recent paper that the relationship between income and subjective well-being is completely different depending on whether the change in income is up or down. Easterlin referred to an asymmetry in the psychological roots of income evaluations when income is rising vs. falling, which in turn causes subjective well-being to respond differently to the direction of the income change.

Therefore, the study of subjective well-being should be addressed from a dynamic viewpoint by examining which factors drive changes in subjective well-being over time (Headey \& Muffels, 2018; Maggino \& Facioni, 2017; Yap et al., 2014), as well as differentiating by the direction of the change (increase or decrease). Despite the importance of this topic, it has been scarcely studied in the related literature and could be considered a challenge for evidence-based public policy regarding subjective well-being (see Odermatt \& Stutzer, 2017).

Bearing this in mind, our main goal is to study changes in subjective well-being in Germany over time distinguishing between long-term (15 years) and short-term changes (annual). Previous studies have shown that not all drivers are able to predict changes in subjective well-being in the same direction and with the same intensity, and that the results may also be different depending on the time horizon (see Bartolini \& Sarracino, 2014; Headey \& Muffels, 2018). More specifically, using longitudinal data from the German Socio-Economic Panel (GSOEP, 1999-2014), we analyse the relationship between variations in economic and social resources and improvements (ups) or declines (downs) in subjective well-being.

Our findings show that social capital, values and cultural dimensions have the greatest capacity to predict changes in subjective well-being in the long term. However, economic resources-especially household income-are the most relevant predictors of changes in subjective well-being in the short term. Likewise, for both time horizons, we find that including personality traits plays a key role.

The remainder of this study is structured as follows. The literature on changes in subjective well-being is reviewed in Sect. 2. The dataset and variables used in the analysis are presented in Sect. 3, where we also analyse the rationale for including these variables in the estimates and review the expected correlation with subjective well-being. The empirical strategy is described in Sect. 4, as well as the specific analysis techniques performed for the long and short term. The main results of the analysis are presented in Sect. 5. Finally, conclusions are drawn in Sect. 6. 


\section{Changes in Subjective Well-Being Over Time}

In the related literature, subjective well-being is defined as the degree to which people think and feel that their life is good, desirable and pleasant, that is, how people evaluate the intensity of their experiences in terms of positive and negative emotions, happiness or satisfaction with life (Diener, 2009; Lucas \& Brent, 2007; Veenhoven, 2017). Subjective well-being is measured by asking individuals to provide a global assessment of their life and domains of life, such as economic resources and social relationships (see, for instance, Ferrer-i-Carbonell \& Frijters, 2004; Di Tella \& MacCulloch, 2008; Dolan \& Metcalfe, 2012). ${ }^{1}$

In studies on subjective well-being from a temporal perspective, set-point theory has been the most widespread approach, especially in the eighties and nineties. Setpoint theory holds that subjective well-being is stable over time primarily due to the stability of personality traits. It might also be due to the strong correlation between these traits and subjective well-being (Diener \& Lucas, 1999) as well as adaptation play (Frederick \& Loewenstein, 1999). This process is known as hedonic adaptation and states that changes in people's living conditions may only have a transitory effect on well-being, since people tend to adapt to their past experiences or new aspirations emerge. Hence, sooner or later, individuals will inevitably return to a set-point after a period of adaptation (Clark et al., 2008; Conceicao \& Bandura, 2008; Di Tella et al., 2010; Frey \& Stutzer, 2002).

In the following decades, however, the study of changes in subjective well-being and its possible determinants has gained more interest largely due to the availability of panel data that enable longitudinal analyses. One of the main branches in the literature has focused on assessing the impact over time of major life events (divorce, unemployment, the death of one's spouse, etc.) on subjective well-being. The main results indicate that major life events can have strong effects on subjective well-being and that the strength of these effects and the patterns of adaptation to these events vary from event to event (see Yap et al., 2014 for a review).

Subsequently, the literature on this topic focused on how changes in different explanatory variables might foster changes in subjective well-being. In this vein, Pedersen and Schmidt (2011) worked with the European Community Household Panel for 15 Member states for eight years (1994-2001). As a novelty, they estimated a multinomial probit model to study changes in subjective well-being between consecutive waves, where the dependent variable took three categories: increase, decrease and no change. They found that the transition from a job to unemployment increases the probability of a reduction in subjective well-being in all the countries, and that better self-reported health status reduces the probability of a decrease in satisfaction. However, they did not reach conclusive results for all the countries regarding the relationship between changes in income (both absolute and relative) and changes in well-being.

Di Tella and MacCulloch (2008) based on Eurobarometer data, Bartolini et al. (2013b) using the GSOEP for Germany and Bartolini et al. (2013a) working with the General Social Survey for the United States followed a very similar empirical approach and predicted changes in subjective well-being for 23, 12 and 32 years, respectively. The main

\footnotetext{
1 In this study, and following Veenhoven (2017), we use the terms "subjective well-being," "happiness," "satisfaction with life," "life satisfaction" and "general satisfaction" as being synonymous.
} 
result reached by Di Tella and MacCulloch (2008) is that increases in income are slightly correlated with increases in subjective well-being. Bartolini et al. (2013b) concluded that not all drivers predict changes in the same direction and with the same intensity. Specifically, they found that increases in social capital predict the largest increase in subjective well-being, whereas increases in population aging predict the largest decrease in subjective well-being. Finally, Bartolini et al. (2013a) considered both social capital and social trust and the predictions they reached are closer to the actual variation recorded in subjective well-being (happiness) compared to Bartolini et al. (2013b). According to the authors, variations in social capital and social trust are the main drivers of changes in subjective wellbeing, and these variations go in the same direction. Regarding economic resources, an increase in absolute income was found to contribute to increases in subjective well-being, whereas an increase in relative income contributes to reducing subjective well-being, with the former being of greater intensity than the latter.

Bartolini and Sarracino (2014) focused on 27 European countries using six waves from different datasets covering 30 years (1980-2009) to analyse the correlation between trends of subjective well-being (happiness and life satisfaction) and social capital and GDP. They observed that social capital is a better predictor of subjective well-being trends in the long (15 years) and medium run (3-6 years), while short-run (two years) changes in GDP have a more positive relationship with subjective well-being.

More recently, some studies could shed light on the relationship between subjective well-being and changes in social capital and economic growth over time, although they do not study the variable of subjective well-being in changes (the main goal of our study). Using the World Values Survey-European Values Study dataset, Mikucka et al. (2017) stated that there is a statistically and positive correlation between economic growth and subjective well-being only in transition countries (transition countries are an exception to the Easterlin paradox). Sarracino and Piekalkiewicz (2021) used the European Social Survey to compare subjective well-being in 22 countries of Western and Eastern Europe for the period 2006-2010. They concluded that the gap is partly associated with an increase in the importance that people attach to income. For these authors, the growing materialism and erosion of social capital that can accompany an economic crisis plays a large role in explaining the decreasing well-being of people in Europe. One of the remarkable aspects of these articles, such as the analysis of different types of countries, is beyond the scope of this study since our research focuses on a single country (i.e. Germany).

Appendix Table 4 highlights the main potentialities and drawbacks we identified in the literature review regarding changes in subjective well-being. Overall, it might be deduced that (1) there are certain limitations in terms of the number of explanatory variables used, which might be due to the availability (or lack) of information analysed in each case; (2) most of the papers do not take into account internal and social comparisons in terms of income as determinants of changes in subjective well-being; and (3) there is a large disparity concerning the time horizon analysed. As a result, the findings are inconclusive: not all drivers predict changes in the same direction and with the same intensity, and the results may also differ depending on the time horizon analysed. Therefore, our study incorporates the potentialities we found in the previous literature and attempts to fill the detected gaps. From a theoretical and conceptual point of view, in addition to socio-demographic control variables, we identified four key groups that should be analysed as determinants of changes in subjective well-being over time: economic resources, social capital, values and cultural dimensions, and personality traits. Likewise, under the umbrella of economic resources, we study the role of absolute income and relative income. That is, we explicitly consider 
the comparisons in terms of income with the own person in the past and with others (social comparisons). From a methodological point of view, following the idea of Bartolini and Sarracino (2014), our analysis distinguishes between long-term (15 years) and short-term changes (year by year) in subjective well-being. To that end, we use different analysis techniques.

\section{Data and Variables}

\subsection{Data}

We employ data from the GSOEP for the period 1999-2014. Following D'Ambrosio and Frick (2012), to control for potential panel effects, we consider the head of household with three or more interviews as a proxy for the interviewing experience in the panel. Additionally, we have only considered individuals with consecutive observations. The final number of observations is 66,527 . We have chosen the GSOEP to investigate changes in subjective well-being over time due to its longitudinal structure and because it includes information about key aspects, such as social comparisons, social capital, values and cultural dimensions, and personality traits.

\subsection{Variables}

\subsubsection{Subjective Well-Being}

The GSOEP gathers information about individuals' satisfaction with life as a whole by means of the following question: 'How satisfied are you with your life, all things considered? Please answer according to the following scale where 0 is completely dissatisfied and 10 is completely satisfied'. It is assumed that people assess their utility and classify it under one of the available categories. This variable is denoted by General Satisfaction. The main descriptive statistics of all the variables for the last year (2014) are reported in Table 1. In line with previous studies, we observe that mean General Satisfaction is 7.06, with a standard deviation of 1.70 on an 11-point scale (see, for instance, Bárcena-Martín et al., 2017; Headey \& Muffels, 2018).

\subsubsection{Explanatory Variables}

As main determinants of subjective well-being and its changes, in the following subsections we focus on (1) economic resources and social comparisons in terms of income; (2) social capital; (3) values and cultural dimensions and (4) personality traits. We would like to stress that the information on the variables that capture social and cultural capital together with personality traits was not collected every year in the GSOEP. In line with Muffels and Headey (2013), we impute the values for the missing year with the immediately preceding year with information and, if this is the first year, we replace it with the first data available. 
Table 1 Descriptive statistics of general satisfaction in Germany and explanatory variables (2014)

\begin{tabular}{|c|c|c|c|c|}
\hline Dependent variable & Mean & SD & Min. & Max. \\
\hline General Satisfaction & 7.060 & 1.697 & 0 & 10 \\
\hline \multicolumn{5}{|l|}{ Economic resources $^{a}$} \\
\hline Absolute Income & 18.53 & 11.69 & 1.135 & 331.1 \\
\hline Adaptation & 18.06 & 11.45 & 0 & 25.28 \\
\hline Relative Deprivation & 0.005 & 0.003 & 0 & 0.138 \\
\hline Relative Affluence & 0.003 & 0.004 & 0 & 0.113 \\
\hline \multicolumn{5}{|l|}{ Social capital } \\
\hline Bonding & 0.388 & 0.487 & 0 & 1 \\
\hline Bridging & 0.349 & 0.178 & 0 & 1 \\
\hline \multicolumn{5}{|c|}{ Values and cultural dimensions } \\
\hline Economic Goals & 0.575 & 0.182 & 0 & 1 \\
\hline Family Goals & 0.776 & 0.226 & 0 & 1 \\
\hline Social Goals & 0.548 & 0.145 & 0 & 1 \\
\hline Worries & 0.460 & 0.244 & 0 & 1 \\
\hline Mistrust & 0.520 & 0.178 & 0 & 1 \\
\hline Risk & 4.641 & 2.286 & 0 & 10 \\
\hline \multicolumn{5}{|l|}{ Personality traits } \\
\hline Neuroticism & 3.682 & 1.193 & 1 & 7 \\
\hline Extraversion & 4.799 & 1.100 & 1 & 7 \\
\hline Openness & 4.553 & 1.169 & 1 & 7 \\
\hline Agreeableness & 5.366 & 0.957 & 1.333 & 7 \\
\hline Conscientiousness & 5.878 & 0.877 & 2.333 & 7 \\
\hline LOC & 3.600 & 0.915 & 1 & 7 \\
\hline Rep_pos & 5.856 & 0.883 & 2 & 7 \\
\hline Rep_neg & 2.972 & 1.401 & 1 & 7 \\
\hline \multicolumn{5}{|c|}{ Socio-economic characteristics } \\
\hline Male & 0.579 & 0.494 & 0 & 1 \\
\hline East & 0.268 & 0.443 & 0 & 1 \\
\hline Young & 0.030 & 0.171 & 0 & 1 \\
\hline Old & 0.444 & 0.497 & 0 & 1 \\
\hline Children & 0.204 & 0.403 & 0 & 1 \\
\hline One adult & 0.291 & 0.454 & 0 & 1 \\
\hline Two adults & 0.570 & 0.495 & 0 & 1 \\
\hline Primary & 0.074 & 0.262 & 0 & 1 \\
\hline Secondary & 0.550 & 0.498 & 0 & 1 \\
\hline Good Health & 0.788 & 0.409 & 0 & 1 \\
\hline Owner & 0.556 & 0.497 & 0 & 1 \\
\hline Employed & 0.589 & 0.492 & 0 & 1 \\
\hline
\end{tabular}

$\mathrm{N}=4,859 .{ }^{\text {a }}$ All income variables are measured in hundreds of euros. Adapted from the German Socio-Economic Panel

3.2.2.1 Economic Resources and Social Comparisons The relationship between economic resources and subjective well-being constitutes a relevant challenge to traditional economics. Due to the benefits of higher prosperity, larger incomes are expected to be associated with greater subjective well-being, especially in the study of short-term changes in sub- 
jective well-being (Bartolini \& Sarracino, 2014). However, Easterlin (1974) showed that increases in income over time are not always associated with increases in subjective wellbeing, what is known as the Easterlin paradox. There is a vast literature explaining this paradox which states that what matters for subjective well-being is not only absolute income, but also the comparisons that individuals make with themselves in the past (internal comparisons) or with others (external or social comparisons) (Clark et al., 2008; D'Ambrosio \& Frick, 2012; Di Tella et al., 2010; Ferrer-i-Carbonell, 2005; Kristoffersen, 2018; Stutzer, 2004; Tsui, 2014; Tsurumi et al., 2019; Wolfers et al., 2012). Concerning internal comparisons, past incomes could also affect current satisfaction; for instance, via wealth. Nonetheless, according to the set-point theory reviewed above, these effects may only be transitory due to the hedonic adaptation process. On the other hand, external benchmarks refer to the idea that comparisons in terms of income are made with respect to others.

The information about income in our dataset allows us to model different measures of economic resources as determinants of subjective well-being. Firstly, Absolute Income is the household income deflated to 2011 prices using the consumer price index provided in the GSOEP and modified by an OECD equivalence scale to control for differences in household size and economies of scale.

Secondly, to study the income adaptation process, related studies have considered different numbers of lags; for instance, three years (Bartolini et al., 2013b; Layard et al., 2009), four years (Di Tella et al., 2010) or even the average of four-year lags (Bárcena-Martín et al., 2017; Di Tella et al., 2010). In this study, we have opted for a four-period lag income to not lose too many observations. This decision implies that 1999-2014 is the period of analysis, although we have data from 1995. We denote this variable as Adaptation.

Finally, to study social comparisons in terms of income, we work under the assumption of asymmetric comparisons. This means that people care differently about comparisons with those who are richer or poorer than them (see, for instance, D'Ambrosio \& Frick, 2012; Bárcena-Martín et al., 2017). When comparing variations in the income of others with variations in reported well-being, both a positive and negative relationship can be found, regardless of whether the comparisons are upward or downward. The upward negative effect could be interpreted as envy, so good news for some people is bad news for others, and an upward positive effect acts as a signal, that is, other people's attainments contain information on how to improve one's own status. For the case of downward comparisons, a negative relationship is interpreted as a compassion effect, and a positive one as a pride effect. Accordingly, we use the variables Relative Deprivation and Relative Affluence to reflect the idea of upward and downward comparisons, respectively.

Likewise, taking into account that individuals in more unequal societies may report, on average, a lower score on the life satisfaction scale (Ferrer-i-Carbonell \& Ramos, 2014; Schwarze \& Härpfer, 2007), an individual with a given income might not feel as happy in a society with high income inequality as in an economy with low income inequality. Like in Ferrer-i-Carbonell (2005), we consider comparisons within a reference group. In line with these authors and the related literature, we define a reference group as all individuals who have a similar educational level, belong to the same age bracket and live in the same region. ${ }^{2}$ Now, based on the formal specification of Yitzhaki (1979) and Hey and Lambert

\footnotetext{
${ }^{2}$ Particularly for education, we use three categories according to the years of formal education: less than 10,10 to 12 and 12 years or more. Similarly, the age brackets are: younger than 25, 25-34, 35-44, 45-65 and 66 or older. The regions are western Germany and the Eastern German Länder. This combination generates 30 different reference groups.
} 
(1980), we define the total deprivation assigned to a person with an income $y_{i t}$ as the sum of all differences between this person's income and the income of all individuals of his/ her reference group whose income is higher, that is, the set of individuals with a higher income than him/her. We use a similar reasoning to measure total affluence, which considers comparisons with all individuals with a lower income, that is, the set of individuals with a lower income than him/her. We then obtain our variables by dividing the differences in income by the number of individuals to whom the income is compared multiplied by the mean of the income distribution. That is, the income gaps are normalised through mean income as proposed by Chakravarty (1997). As pointed out by D'Ambrosio and Frick (2012), this normalisation could be more appropriate for comparing different time periods or different societies.

We denote $y_{i t}$ than $y_{j t}$ as the level of individual $i$ and $j$ at time $t$ who belong to the same reference group $R_{i} \cdot \bar{y}_{t}$ is defined as the average income of the reference group. To correct the possibility of having very small differences among incomes and therefore a person with a slightly lower $y_{i t}$ than $y_{j t}$ may not feel deprivation, we consider a margin $h$ over the average income in those reference groups with lower income variability. We define the individual $i$ better-off set of individuals as $B_{i}\left(y_{i t}\right)=\left\{j \in R_{i} \mid y_{i t}>y_{i t}\right\}$ and the worse-off set as $W_{i}\left(y_{i t}\right)=\left\{j \in R_{i} \mid y_{j t}<y_{i t}\right\}$. Hence, we build the indicators Relative Deprivation $\left(D_{i t}\right)$ and Relative Affluence $\left(A_{i t}\right)$ as follows ${ }^{3}$ :

$$
\begin{aligned}
& D_{i t}\left(y_{i t}, \mathrm{y}_{j t}\right)=\left\{\begin{array}{l}
\frac{\sum_{\mathrm{j} \in \mathrm{B}_{\mathrm{i}}(y)}\left(y_{j t}-y_{i t}\right)}{n \bar{y}_{t}} \text { if } \mathrm{y}_{\mathrm{it}}<\mathrm{y}_{\mathrm{jt}} \text { and } y_{i t} \notin\left[-h \bar{y}_{t}, h \bar{y}_{t}\right] \\
0 \text { if } \mathrm{y}_{\mathrm{it}} \geq y_{j t} \quad \text { or } y_{i t} \in\left[-h \bar{y}_{t}, h \bar{y}_{t}\right]
\end{array}\right. \\
& \text { and } A_{i t}\left(y_{i t}, \mathrm{y}_{j t}\right)= \begin{cases}\frac{\sum_{\mathrm{j} \in \mathrm{W}_{\mathrm{i}}(y)}\left(y_{i t}-y_{j t}\right)}{n \bar{y}_{t}} & \text { if } \mathrm{y}_{\mathrm{it}}>y_{j t} \text { and } y_{i t} \notin\left[-h \bar{y}_{t}, h \bar{y}_{t}\right] \\
0 \text { if } \mathrm{y}_{\mathrm{it}} \leq y_{j t} & \text { or } y_{i t} \in\left[-h \bar{y}_{t}, h \bar{y}_{t}\right]\end{cases}
\end{aligned}
$$

3.2.2.2 Social Capital Social capital refers to the capacity of people to build a social network and engage in interpersonal activities (Helliwell \& Putnam, 2004; Muffels \& Headey, 2013). Under the network approach of social capital (see Woolcock \& Narayan, 2000), two dimensions are considered: bonding and bridging social capital. Bonding social capital refers to closed networks, strong ties or horizontal associations (within). To capture this, we considered 'the frequency of meetings with family and friends'. Bridging social capital refers to cross-cutting ties, weak ties or vertical associations (between). In this vein, we consider attendance to the following social events: social gatherings, cultural events, cinema, pop or jazz concerts, sports activities, religious events, participation in local politics and volunteer work. Studies on changes in subjective well-being have shown that people with increasing social relationships tend to be happier with their lives because they find affective support and information about economic opportunities (Bartolini \& Sarracino, 2014; Bartolini et al., 2013a, 2013b).

The GSOEP asks respondents about the frequency with which they meet with family and friends and their participation in different types of events. The respondents can respond

\footnotetext{
${ }^{3}$ For any other commonly used measures of deprivation and affluence see the Online Appendix. We will also present results for them as robustness checks in the Results section.
} 
according to the following frequencies relative to the above indicators: 1 every day, 2 every week, 3 every month, 4 less frequently or 5 never. Following Sabatini (2009) and Bartolini and Sarracino (2014), we construct the dummy variable Bonding, which takes the value of 1 if the respondent meets with relatives and friends at least once a month. Bridging social capital is measured by an index constructed with the individual's responses regarding attendance to social gatherings, cultural events, cinema, pop or jazz concerts, church or other religious events, participating in sports, performing volunteer work and participating in local politics (see Bárcena-Martín et al., 2017). We recode these variables so that 'every day' corresponds to the highest value in the scale and the category 'never' corresponds to the lowest one. We use principal component analysis and, normalising between 0 and 1 , we obtain the variable Bridging. ${ }^{4}$ Table 1 indicates that $38.8 \%$ and $35 \%$ of our sample enjoy bonding and bridging social capital, respectively.

3.2.2.3 Values and Cultural Dimensions In line with Diener (2009) and Schimmack et al. (2002), our approach is that subjective well-being is determined by economic, social, and psychological factors, as well as cultural characteristics. The cultural dimension in subjective well-being studies has been considered above all to determine whether people from different cultures have different conceptions of well-being.

Cultural factors shape personal values and individuals' desirable goals in life (Schwartz, 2017; Schwartz \& Sortheix, 2018). Personal values represent what people consider important and worth pursuing in life and given that subjective well-being represents how happy and satisfied people are with the life they are leading, the study of the relationships between personal values and subjective well-being should be of great interest (Schwartz \& Sortheix, 2018). In this setting, several studies have examined the relationship between personal values/life values and subjective well-being and concluded that the motivation to pursue goals is tailored in an important way by the culture in which people live (Brdar et al., 2009; Chebotareva, 2015; Oishi \& Diener, 2009; Schimmack et al., 2002; Schwartz \& Sortheix, 2018). Additionally, Lareau and Weininger (2003) developed a concept of cultural capital which refers to the operational skills, values in life and behavioural norms that one accrues through education and life-long socialisation.

As proxy variables of values and cultural dimensions, we include the following items that represent values in which people differ for cultural reasons (see Schwartz et al., 2000; Schwartz, 2017; Schwartz \& Sortheix, 2018): life goals, Worries, Mistrust, and Risk. Firstly, as life goals, we consider Economic Goals associated with the values of power and achievement; Family Goals that are representative of values of tradition, security-societal and hedonism; and Social Goals referred to benevolence, universalism, stimulation, and self-direction. The GSOEP provides information about economic goals (being able to afford to buy something for yourself, being successful in your career and having a home and affording things), family goals (having a happy relationship and having children) and social goals (being there for others, being politically and/or socially involved, seeing the world and/or travelling extensively, and being self-fulfilled). All these questions are of the type 'Importance of' and the responses take values from 1 very important to 4 not at all important. Rearranging this scale and using principal component analysis, we synthesise the maximum amount of information in the three categories. The categories are then

\footnotetext{
${ }^{4}$ To account for the maximum data variance, the Bridging variable is an index that, in accordance with Peters and Butler (1970), synthesises principal components with an eigenvalue higher than 1 (Kaiser's approach).
} 
normalised between 0 and 1 and we obtain the variables Economic Goals, Family Goals and Social Goals (for similar variables, see Muffels and Heady, 2013; Bárcena-Martín et al., 2017; Headey \& Muffels, 2018; Navarro \& Sánchez, 2018).

Secondly, taking into account studies which have shown that concern for the general situation of all people (for instance, the economic situation) and the environment might affect subjective well-being (Bárcena-Martín et al., 2017; De Neve et al., 2018; Easterlin, 2021; Macchia \& Oswald, 2021; Navarro \& Sánchez, 2018), we include the variable Worries. Worries reflects people's concerns about economic development, finances, peace and the environment. These concepts reflect the personal values of (economic) security, as well as universalism-concern and universalism-nature, which are defined as protection for the welfare of all and the environment, respectively (Schwartz, 2017; Schwartz \& Sortheix, 2018). The GSOEP includes questions regarding these issues that take values from 1 if the respondent is very concerned to 3 if the respondent is not at all concerned. Again, we rearrange this scale and use principal component analysis to obtain the Worries variable, which is also normalised from 0 to 1 .

Thirdly, we also build a variable concerning trust, which includes information related to trust in other people. More specifically, we build the variable Mistrust that reflects the cultural background of a person in terms of individual attitudes and values of wariness in people in general and foreigners in particular. To build this variable, the GSOEP collects the degree of agreement or disagreement with statements such as 'nowadays you cannot trust anyone' or 'take caution with foreigners'. The responses to these questions take values from 1 totally agree to 4 totally disagree. Rearranging this scale and using principal component analysis, we summarised the maximum variance and normalised it from 0 to $1 .^{5}$ The concepts included in the variable Mistrust are associated with the personal values of safety, that is, social harmony and stability (social order, for instance), as well as universalism in the sense of understanding and tolerance. Within the concept of universalism, as pointed out by Schwartz and Sortheix (2018), values such as supporting immigration could be considered. Unlike social capital, which refers to the capacity of people to build a social network and engage in activities with people to whom they relate (closer people such as family members or more distant ones such as co-workers) (Helliwell \& Putnam, 2004; Muffels \& Headey, 2013; Woolcock \& Narayan, 2000), Mistrust refers to the positioning of a person with respect to people or society in general and not with respect to known people (in the same vein, see Rözer \& Kraaykamp, 2013; Navarro \& Sánchez, 2018). Such positioning partially reflects people's cultural norms and economic situation (Brdar et al., 2009; Chebotareva, 2015). In this regard, it is worth noting that several studies in the related literature have included trust in individuals as a part of social capital (Bartolini \& Sarracino, 2014; Mikucka et al., 2017; Sarracino and Piekalkiewicz, 2021). In accordance with the conceptual framework adopted in this study, we consider Mistrust as a part of values and cultural dimensions.

Finally, given that aspects such as parental background have a significant impact on the willingness to take risks (Dohmen et al., 2011), it is usual to consider a variable reflecting the risk willingness of people as a part of cultural capital in subjective well-being studies (see, for instance, Conceicao \& Bandura, 2008; Muffels \& Heady, 2013; Navarro \& Sánchez, 2018). The GSOEP includes the specific question: 'Are you

\footnotetext{
5 The Economic Goals, Family Goals, Social Goals, Worries and Mistrust variables are indexes built in accordance with Peters and Butler (1970). They synthesise the principal components with an eigenvalue higher than 1 (Kaiser's approach).
} 
a person who is generally willing to take risks or do you try to avoid taking risks?'. The responses take values from 0 to indicate lower risk willingness (i.e. none) to 10 referring to higher risk willingness (i.e. very). We denoted this variable as Risk, which is standardised to take a mean 0 and variance 1 . Risk is linked to the personal value of stimulation, which is defined as excitement, novelty, and challenge in life (daring, a varied life, an exciting life) (Schwartz et al., 2000). The willingness to take risks (for instance, to change one's job, career, or business) will depend on the importance that people attach to the value of stimulation, as well as other cultural norms such as tradition (Is it common to change jobs or companies in that culture?).

To sum up, the reviewed literature indicates that personal values and life goals are largely determined by people's cultural models, such that people with different positions on these concepts may hold diverse views of subjective well-being (Gelati et al., 2006; Schwartz \& Sortheix, 2018). Therefore, in the study of changes in subjective wellbeing over time it is interesting to incorporate the proxies of these values and cultural dimensions.

Table 1 indicates that the proportion of people who attach importance to their family, economic and social goals is $77.6 \%, 57.5 \%$ and $54.8 \%$, respectively. We also observe that around half of individuals are concerned about issues related to economic development, finances, peace and the environment and feel mistrust when dealing with other people, and, on average, the willingness to take risks is about 4.64 over 10.

3.2.2.4 Personality Traits Personality traits as part of psychological capital incorporate the so-called Big Five Indicators (BFI) of neuroticism, extraversion, openness, agreeableness and conscientiousness; the LOC index as an external measure of the degree of control over one's life; and a reciprocity measure (negative and positive). The existing results at level show that more extraverted, open, agreeable, conscientious and less neurotic people are happier. In addition, a negative relationship is expected between subjective well-being and both LOC and negative reciprocity, whereas a positive relationship is expected between subjective well-being and positive reciprocity (Bárcena-Martín et al., 2017; Budría \& Ferrer-iCarbonell, 2019). The inclusion of personality traits among the determinants of changes in well-being is key, since, as discussed in a previous section, the stability of personality traits and their strong correlation with subjective well-being is one of the foundations of set-point theory (Diener \& Lucas, 1999). Hence, personality traits should be considered at least as control variables in the analysis of changes in subjective well-being.

More specifically, we include the same type of indicators to measure personality traits as in Budría and Ferrer-i-Carbonell (2019), namely the BFI, the LOC index on external measures to measure the degree of control over life and a positive (Rep_Pos) and negative (Rep_Neg) reciprocity measure. The five personality traits of the BFI are obtained after aggregating across a total of 15 items provided by the GSOEP. In addition, some items are recorded because a higher score negatively correlates with the specific dimension under evaluation. The LOC index is surveyed in the GSOEP by means of a total of 10 items, of which six measure external LOC. Positive and negative reciprocity measures are modelled by aggregation across three items each of these variables. All these variables take values on a scale of 1 if the respondent states that it 'does not apply' (i.e. the respondent considers that he/she does not have that personality trait) to 7 if the respondent states that it 'does apply' (i.e. the respondent considers that he/she has that personality trait). To facilitate the interpretation of the results, BFI, LOC, Rep_Pos and Rep_Neg are standardised to take mean zero and unit variance. As can be observed in Table 1, the individuals in 
our sample are more conscientious (5.88 on average) and exhibit less negative reciprocity towards other people (2.97 on average).

3.2.2.5 Socio-Economic Characteristics As control variables, we consider the socio-economic characteristics commonly used in the literature. We construct the dummy variable Male, which takes the value of 1 if the respondent is male. The variable East takes the value of 1 if the respondent lives in the Eastern German Länder. To measure the respondent's age, we define the dummy variables Young and Old, which take the value of 1 if the respondent is younger than 30 or older than 60 , respectively. To capture marital status and household size, we include the dummy variables One adult and Two adults, which take the value of 1 if there is only one or two adults in the household, and the dummy variable Children, which takes the value of 1 if there is one or more children in the household. The dummy variables Primary and Secondary take the value of 1 if the respondent has a primary or secondary level of education, respectively. The dummy variable Good Health takes the value of 1 if the respondent states that he/she has at least a satisfactory current health status. The dummy variable Owner takes the value of 1 if the respondent currently owns a dwelling. To capture information for employment status, we define the dummy variable Employed, which takes the value of 1 if the respondent was employed in the previous year.

As shown in Table 1, firstly, on average, almost $60 \%$ of the respondents in our sample are males, own a dwelling, are employed and live with a partner. Second, we also observe that $27 \%$ of respondents are from the Eastern German Länder. Third, 50\% of respondents are older than 60, whereas respondents younger than 30 years old account for almost $20 \%$ of our sample. Fourth, the households in our sample are divided almost evenly between one- and two-adult households and, on average, there is at least one child in $40 \%$ of households. Fifth, almost $50 \%$ of the respondents have a secondary level of education, whereas only $26 \%$ have a primary level. Finally, almost $80 \%$ of our sample reports good health.

\section{Empirical Strategy}

From the review of the literature carried out above, we deduce that in order to study how subjective well-being might be improved over time, we should distinguish between the long- and the short-term analysis of changes in subjective well-being. Thus, our main goal is to identify the determinants of changes in subjective well-being for both time horizons using different analysis techniques.

\subsection{Changes in the Long Term}

Based on Di Tella and MacCulloch (2008) and Bartolini et al. (2013a, 2013b), we try to predict changes in subjective well-being over the period 1999-2014. For this purpose, we perform a linear prediction by calculating changes in subjective well-being motivated by variations in the statistically significant variables over the period. This allows us to provide evidence about how changes in these variables explain changes in subjective well-being. Nonetheless, it is not the only technique available to analyse changes. For instance, Brockmann et al. (2009), Bartolini and Sarracino (2015) and Sarracino and Piekalkiewicz (2021) used a Blinder-Oaxaca decomposition to address this issue. As pointed out by Di Tella and MacCulloch (2008) and Bartolini et al. (2013b), although similarities among techniques 
for prediction and decomposition may be misleading, in which the former can be understood as just a decomposition, it would not be the case when using this prediction method for three main reasons. First, this methodology does not use all estimated coefficients, but only those that turn out to be statistically significant at the $10 \%$ level at least. Secondly, while the baseline in our regression does not include weights, they are introduced in the prediction. Thus, the variation used to estimate the baseline regression is different from that used to obtain the predictions. Finally, this approach can lead to predictions that are far away from the observed values because the addition of regressors with significant coefficients does not necessarily improve the precision of the prediction. Hence, our choice of prediction techniques is motivated by the previous reasons.

In this vein, we first estimate general satisfaction at level in terms of the covariates: economic resources, social comparisons, social capital, values and cultural dimensions, and personality traits. Following the proposal of Van Praag and Ferrer-i-Carbonell (2008), we cardinalise our ordered categorical dependent variable. Given that the ordinal scale has no interpretation other than reporting higher or lower satisfaction, we transform the original subjective well-being variable into a numerical evaluation. In other words, we assume that respondents interpret the evaluations in cardinal terms. Although the choice of ordinality versus cardinality is irrelevant in terms of trade-offs between explanatory variables (Ferreri-Carbonell \& Frijters, 2004), cardinality has the advantage of directly interpreting coefficients as marginal effects. As developed by van Praag and Ferrer-i-Carbonell (2008), we assume that subjective well-being in the form of General Satisfaction is a function that, after a proper transformation, follows a normal distribution with mean 0 and variance $1 .^{6}$ Let us derive the $\left\{\mu_{s}\right\}_{s=0}^{S}$ values of a standard normal distribution associated with the cumulative frequencies of the $\mathrm{S}$ different categories of the dependent variable, with $\mu_{0}=-\infty, \mu_{S}=\infty$. The expectation of a standard normally distributed variable is then taken for an interval between any two adjacent values. Thus, if the true unobserved continuous variable for individual $i$ is $G S=s$ if $\mu_{s-1}<G S_{i}^{*} \leq \mu_{s}=\frac{n\left(\mu_{s}-n \mu_{s}\right)}{e\left(\mu_{s-1}-N \mu_{s}\right)}$ for $\mathrm{s}=1, \ldots, \mathrm{S}$, then the conditional expectation of the latent variable is:

$$
\overline{G S_{i}}=E\left(\mu_{s-1}<G S_{i}^{*} \leq \mu_{s}\right)=\frac{n\left(\mu_{s}-n \mu_{s}\right)}{e\left(\mu_{s-1}\right)-N \mu_{s}}
$$

where $\mathrm{n}$ is the normal density and $\mathrm{N}$ is the cumulative normal distribution. This approach allows applying a linear estimator on the conditional expectations, which is assumed to be a function of observable characteristics.

We first estimate the parameters of the following model at level:

$$
\overline{G S}_{i t}=\alpha+y_{i t} \beta_{1}+y_{i t-4} \beta_{2}+D_{i t} \beta_{3}+A_{i t} \beta_{4}+\beta_{5}^{\prime} S C_{i t}+\beta_{6}^{\prime} V C_{i t}+\beta_{7}^{\prime} P T_{i t}+\beta_{8}^{\prime} X_{i t}+\gamma^{\prime} D T_{i t}+\varepsilon_{i t}
$$

where $i=1, \ldots, \mathrm{N}$ denotes the individual and $t=1, \ldots, \mathrm{T}$ is the year. $\overline{G S_{i t}}$ is the General Satisfaction reported by individual $i$ in year $t ; y_{i t}$ refers to the variable Absolute Income; $y_{i, t-4}$ is the four-period lagged income, that is, hedonic adaptation (Adaptation); $D_{i t}$ and $A_{i t}$ denote

\footnotetext{
6 This method is known as probit-adapted ordinary least squares (POLS) and was developed by van Praag and Ferrer-i-Carbonell (2008). Riedl and Geishecker (2014) used Montecarlo simulations to compare different estimation strategies of ordered response models in the presence of non-random unobserved heterogeneity. They found that POLS performs well with a three-, seven- and eleven-point scale ordered response variable.
} 
the social comparisons between individual $i$ 's income and individual $j$ 's income depending on whether the individual compares him/herself with others that are better off (Relative Deprivation) or worse off (Relative Affluence); $S C_{i t}, V C_{i t}, P T_{i t}$ and $X_{i t}$ are matrices that capture the observations of individual $i$ in year $t$ for each of the variables that make up social capital, values and cultural dimensions, personality traits and socio-economic characteristics, respectively; $\beta$ are parameter vectors corresponding to each of those sets of variables; $D T_{t}$ includes time dummies which account for annual changes that are the same for all people to control for fixed effects and, to some extent, the year in which each individual has been introduced into the sample; and $\varepsilon_{i t}$ is the error term.

The error term $\varepsilon_{i t}$ is assumed to be $\varepsilon_{i t}=\vartheta_{i}+\pi_{i t}$, where $\vartheta_{i}$ is the individual timeinvariant effect and $\pi_{i t}$ is an independent error term with $\vartheta_{i} \sim N\left(0, \sigma_{\omega}^{2}, \pi_{i t} \sim N(0,1)\right)$ and $\operatorname{Cov}\left(\vartheta_{i}, \pi_{i t}\right)=0$. In this setting it is assumed that the error term is random and not correlated with the observable explanatory variables. However, this may not be plausible given the potential correlations between individual unobserved characteristics and the explanatory variables. A relevant and widely used solution to address this issue (individual heterogeneity) is that proposed by Mundlak (1978) as justified in Ferreri-Carbonell and Frijters (2004) and Ferrer-i-Carbonell (2005). This method decomposes the individual random effect $\vartheta_{i}$ into two terms: (i) the pure error term $\omega_{i}$ which is normally distributed with zero mean and independent of the idiosyncratic error $\pi_{i t}$ (that is, $\omega_{i} \sim N\left(0, \sigma_{\omega}^{2}\right), \pi_{i t} \sim N(0,1)$ and $\left.\operatorname{Cov}\left(\omega_{i}, \pi_{i t}\right)=0\right)$; and a part that is correlated with a subset of observable time-varying regressors $z_{i t}$ with correlation $\lambda \bar{z}_{i}$ where $\bar{z}_{i}$ is the average of $z_{i t}$ across time. The subset of variables $z_{i t}$ includes variables that vary over time such as family income, years of education and members of the household. We are aware of possible endogeneity problems which would not be corrected solely with Mundlak's correction. Thus, caution should be taken in interpreting the results.

Second, using the estimated parameters from Eq. (1), we try to predict changes in subjective well-being in the long term. The model can be specified as follows:

$$
\Delta \overline{G S}=\sum \beta\left(Z_{2014}-Z_{1999}\right)
$$

where $\Delta \overline{G S}$ is the predicted change in General Satisfaction for the period 1999-2014; $\beta$ is the vector that captures a selected set of coefficients estimated from Eq. (3) that are significantly different from zero; and $Z_{2014}$ and $Z_{1999}$ are the average weighted values of each variable in 2014 and 1999, respectively, except for the time dummies and Mundlak's term. As mentioned above, this prediction procedure is not just a simple decomposition of variation for at least two reasons. First, we only select the estimated coefficients that are statistically significant at a level of at least $10 \%$. And, secondly, we calculate the variations in the variables using the weights provided in the GSOEP.

\subsection{Changes in the Short Term}

Focusing on the determinants of changes in subjective well-being in the short run (annual changes), we estimate a multinomial logit model. As the proxy of Mundlak's correction included estimating the level, we use the Chamberlain-Mundlak terms when estimating the multinomial logit models. That is, we include the average of each explanatory variable for each individual over time. To define short-term changes in subjective well-being, we adapt the indicator proposed by Bandyopadhyay and Yalonetzky (2016). This indicator allows assessing multiple-period mobility as the average distance travelled across categories to 
observe not only the number of 'jumped' categories, but also the direction of the change. ${ }^{7}$ Thus, the dependent variable can take three possible categories: increase, decrease or maintain subjective well-being. We include the changes or first differences in variables which undergo significant annual changes as explanatory variables, while the remaining variables are included at level. ${ }^{8}$ This equation can be written as:

$$
\operatorname{Pr}\left(\Delta G S_{i t, j}^{*}=j\right)=F\left(\eta^{\prime} \Delta W_{i t}+\delta^{\prime} M_{i t}+\omega^{\prime} C M_{i}+\pi_{i t}\right)
$$

where $j=$ increase, decrease and maintain, that is, the mobility indicator is positive, negative and zero, respectively; $\Delta G S_{i t, j}^{*}$ captures changes in General Satisfaction; $\Delta W_{i t}$ denotes all changes in the variables through first differences; $M_{i t}$ includes the level of all variables which do not change over time; $C M_{i}$ contains the Chamberlain-Mundlak terms; and $\pi_{i t, j}$ is the error term.

\section{Results}

\subsection{Subjective Well-Being Changes in the Long Term}

The results for subjective well-being at level (Eq. 3) indicate that the signs and the statistical significance of the estimated parameters are similar to those of previous studies. The results are presented in Appendix Table 5. We find that absolute income and General Satisfaction are positively correlated. The Adaptation parameter is not significant, thus indicating that the adaptation is complete. Additionally, we confirm that there are asymmetric comparison effects, since in the upward comparisons more deprived individuals feel envy (negative association between Relative Deprivation and General Satisfaction) and in the downward comparisons those experiencing affluence show pride (positive association between Relative Affluence and General Satisfaction). We also observe that social capital and values and cultural dimensions are positively correlated with General Satisfaction. Concerning personality traits, being less neurotic or more extraverted, open, agreeable, conscientious and higher positive reciprocity and lower negative reciprocity are also associated with higher levels of General Satisfaction. Moreover, people with a lower LOC (they think that external circumstances play a small role in their life) report higher satisfaction.

Based on Eq. 4, we estimate four models of predicted changes in General Satisfaction in the long term. The results are shown in Table 2, where column 2 reports the effective change recorded by the different concepts studied in the period 1999-2014 (i.e. the difference between the value recorded in 2014 and 1999). Columns 3-6 show the predicted change of General Satisfaction and its determinants for different specifications using Eq. 2. ${ }^{9}$ In this section, and in the following one, we present the results of our estimations

\footnotetext{
7 The authors define this indicator as $d_{n t}=\frac{\left|x_{n t}-x_{n, t=1}\right|}{S-1}$, for $n=1 \ldots \mathrm{N}, t=1 \ldots \mathrm{T}$ where $x_{n t}$ is subjective wellbeing and $S-1$ is the extreme categories of subjective well-being. We use the same indicator but taking the first difference of subjective well-being without absolute value.

${ }^{8}$ To identify which variables are included in changes, that is, in first differences, we focus on the proportion of zeros in the first differences of each variable. Specifically, we select those variables with less than $80 \%$ of zeros as time-varying variables.

${ }^{9}$ To analyse the robustness of the results, the same models have been estimated with another similar dependent variable ('Satisfaction with life today'). The results are very similar. They will be provided upon request.
} 
Table 2 Prediction of general satisfaction in Germany, 1999-2014

\begin{tabular}{|c|c|c|c|c|c|}
\hline & $\Delta 1999-2014$ & Model 1 & Model 2 & Model 3 & Model 4 \\
\hline Total change & 0.031 & -0.003 & -0.057 & -0.005 & 0.017 \\
\hline Economic resources & & 0.004 & 0.005 & 0.004 & 0.005 \\
\hline Absolute Income & 0.006 & 0.007 & 0.008 & 0.007 & 0.008 \\
\hline Adaptation & 0.007 & & & & \\
\hline Relative deprivation & 0.052 & -0.005 & -0.005 & -0.004 & -0.004 \\
\hline Relative affluence & 0.037 & 0.002 & 0.002 & 0.001 & 0.001 \\
\hline Social capital & & & -0.052 & -0.045 & -0.042 \\
\hline Bonding & 0.033 & & 0.001 & 0.001 & 0.001 \\
\hline Bridging & -0.126 & & -0.053 & -0.046 & -0.043 \\
\hline Values and cultural dimensions & & & & 0.046 & 0.042 \\
\hline Economic goals & -0.053 & & & & \\
\hline Family goals & -0.055 & & & -0.005 & -0.005 \\
\hline Social goals & 0.016 & & & 0.004 & 0.003 \\
\hline Worries & -0.083 & & & 0.037 & 0.035 \\
\hline Mistrust & -0.027 & & & 0.007 & 0.000 \\
\hline Risk & 0.109 & & & 0.003 & 0.003 \\
\hline Personality traits ${ }^{l}$ & & & & & 0.025 \\
\hline Neuroticism & -0.223 & & & & 0.017 \\
\hline Extraversion & 0.065 & & & & 0.001 \\
\hline Openness & 0.140 & & & & 0.002 \\
\hline Agreeableness & -0.092 & & & & -0.003 \\
\hline Conscientiousness & -0.037 & & & & -0.001 \\
\hline LOC & -0.144 & & & & 0.009 \\
\hline Rep_pos & -0.042 & & & & -0.001 \\
\hline Rep_neg & -0.058 & & & & 0.001 \\
\hline Socio-economic characteristics ${ }^{\mathrm{a}}$ & -0.007 & -0.010 & -0.010 & -0.013 & \\
\hline
\end{tabular}

$\mathrm{N}=66,527$. Rows without information correspond to a variable which was not statistically significant in Eq. 1

considering a margin $h$ of $10 \%$ in the social comparisons in terms of income $\left(D_{i t}\right.$ and $\left.A_{i t}\right) .{ }^{10}$ Models 1 to 4, in addition to socio-economic characteristics, progressively incorporate the different groups of explanatory variables, namely economic resources, social capital, cultural capital and personality traits.

As a starting point, we observe that throughout the 15 years studied, the actual data show that General Satisfaction has improved (0.031). Although the change could be seen as small, it is significant. Related evidence shows that subjective well-being is a measure

\footnotetext{
${ }^{10}$ The results considering a margin of 5\% and of $0 \%$ for Relative Deprivation and Relative Affluence are available in the Online Appendix. Additionally, we performed the analysis defining other specifications to measure social comparisons. More specifically, for the second comparison we only included the standard measure of Ferrer-i-Carbonell (2005), while the third comparison considered absolute deprivation and affluence ( simply the sum of the gaps between an individual's income and the incomes of all individuals richer or poorer than him/her, respectively). The results of these measures are similar to those presented in the main text. For more details, see the Online Appendix.
} 
with extremely low variability. In our work, the original variable of subjective well-being registers a standard deviation of 1.799 on an 11-point scale, whereas the cardinalised variable shows a standard deviation of 0.905 on a 5 -point scale, which is in line with previous studies. Thus, the actual change is one third of the standard deviation. However, as pointed out in previous studies (for instance, in Bartolini et al., 2013b), small changes in subjective well-being are normally very relevant, in which even a $0.1 \%$ change in this measure deserves careful consideration.

Comparing the predictive capacity of the different models, the best specification corresponds to Model 4, which includes all the groups of explanatory variables. Likewise, from this comparison we could first argue that concepts of social capital and cultural capital should be analysed jointly to reach a better prediction (see the difference between models 2 and 3). In fact, the dividing line between these two concepts is not clearly established in the literature (see for instance, Bartolini et al., 2013a; Neira et al., 2018; Chica-Olmo et al., 2020). Second, and above all, the inclusion of personality traits allows us to reach predictions closer to the changes actually recorded.

Focusing on our proposed specification (Model 4), which gives us the best prediction of changes in satisfaction in the long term, we find that the prediction goes in the same direction as the actual change in General Satisfaction (0.017). This indicates that we have been able to predict $55 \%$ of the actual change. We observe that the main determinants of longterm changes in satisfaction are Bridging (social capital), Worries and Mistrust (values and cultural dimensions) and Neuroticism and LOC (personality traits). Regarding the variable Bridging, the negative prediction is justified by the reduction in the social environment of contacts other than family and friends. In reference to values and cultural dimensions, the reduction in individuals' concern about economic development, peace and financial and environmental issues, together with a reduction in distrust of other people would explain the improvement in General Satisfaction. Concerning personality traits, the finding that people consider themselves to be less neurotic and with greater control over their lives contributes to greater reported satisfaction. Absolute income has a smaller influence, largely because the income levels of households varied only slightly during the period analysed (a time of economic crisis). Feelings of envy are stronger than pride; thus, social comparisons contribute to a decline in General Satisfaction. Therefore, the positive correlation between increases in household income and increases in General Satisfaction is weaker due to comparisons of income with richer people, which partially offset this positive effect.

\subsection{Subjective Well-Being Changes in the Short-Term}

Before presenting the results of the short-term changes, it is worth noting the annual variability of subjective well-being over time. Figure 1 displays data for the whole period (1999-2014) to illustrate the proportion of annual changes (increases and decreases) in General Satisfaction. Specifically, the $y$ axis shows the percentage of people who experience ups or downs in General Satisfaction depending on if the first difference of this variable is positive or negative, respectively. This provides evidence that the percentage of people who experience an improvement and a decline in satisfaction vary year after year. These findings would justify conducting an empirical analysis on the determinants of annual changes in General Satisfaction using a multinomial logit estimation (Eq. 5), which will allow us to study the association between changes in various concepts and increases and decreases in subjective well-being. 


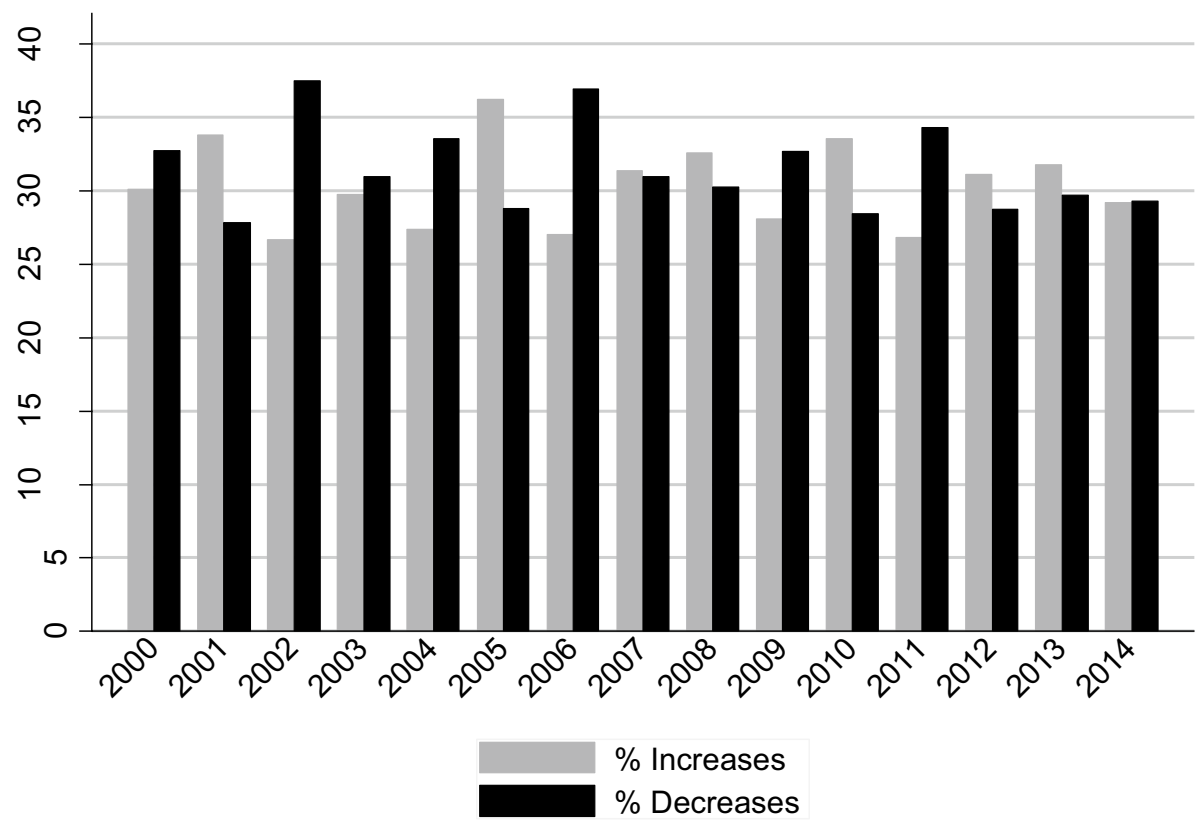

Fig. 1 Percentage of individuals who show improvements and declines in general satisfaction in Germany, 1999-2014. Note. Adapted from the German Socio-Economic Panel

Table 3 shows the results of the multinomial logit estimation. ${ }^{11}$ As we pointed out in a previous section, in these estimations we include the changes or first differences in variables which undergo a large number of annual changes as explanatory variables, whereas the remaining variables are included at level. For this reason, our comments focus on the former. It is also important to mention that to avoid the effect of very small changes in income, we disregard any change lower than $1 \%$ in all the variables that include income in their differences.

Our reference category is the situation in which General Satisfaction does not change in the short term. Our results show, firstly, that the changes in several variables are associated with the probability of both improvements (ups) and declines (downs) in General Satisfaction. More specifically, individuals with annual increases in Absolute Income, in social capital in environments other than family and friends (Bridging) and in risk attitudes (Risk) are more likely to report improvements in General Satisfaction and, at the same time, less likely to report a worsening of General Satisfaction. On the other hand, those who show increased concern about economic development, peace, finances and the environment (Worries) are more likely to report decreased satisfaction and, at the same time, less likely to report improvements in their satisfaction. Secondly, annual changes in some variables are only associated with changes in satisfaction in a single direction. For instance, people who feel deprivation are more likely to report a decline in General Satisfaction, whereas people who attach more importance to their social goals over time are less likely to report

\footnotetext{
11 As a robustness analysis of the results, the multinomial logit model with the dependent variable ("Satisfaction with life today") has been estimated. The results are similar. They will be provided upon request.
} 
Table 3 Multinomial logit estimation on annual changes in general satisfaction in Germany, 1999-2014

\begin{tabular}{|c|c|c|}
\hline Variables & Positive changes $^{\mathrm{a}}$ & Negative changes $^{b}$ \\
\hline \multicolumn{3}{|l|}{ Economic resources } \\
\hline$\Delta$ Absolute income & $\begin{array}{l}0.667 * \\
(0.376)\end{array}$ & $\begin{array}{l}-0.790 * \\
(0.453)\end{array}$ \\
\hline$\Delta$ Adaptation & $\begin{array}{l}0.293 * \\
(0.171)\end{array}$ & $\begin{array}{l}-0.091 \\
(0.177)\end{array}$ \\
\hline$\Delta$ Relative deprivation & $\begin{array}{l}-0.029 \\
(0.024)\end{array}$ & $\begin{array}{l}0.041^{*} \\
(0.025)\end{array}$ \\
\hline$\Delta$ Relative affluence & $\begin{array}{l}0.034 \\
(0.022)\end{array}$ & $\begin{array}{l}-0.012 \\
(0.027)\end{array}$ \\
\hline \multicolumn{3}{|l|}{ Social capital } \\
\hline Bonding & $\begin{array}{l}0.003 \\
(0.007)\end{array}$ & $\begin{array}{l}0.004 \\
(0.007)\end{array}$ \\
\hline$\Delta$ Bridging & $\begin{array}{l}0.089^{* *} \\
(0.032)\end{array}$ & $\begin{array}{l}-0.160 \text { *** } \\
(0.033)\end{array}$ \\
\hline \multicolumn{3}{|c|}{ Values and cultural dimensions } \\
\hline$\Delta$ Economic goals & $\begin{array}{l}0.037 \\
(0.039)\end{array}$ & $\begin{array}{l}-0.057 \\
(0.037)\end{array}$ \\
\hline$\Delta$ Family goals & $\begin{array}{l}0.014 \\
(0.030)\end{array}$ & $\begin{array}{l}0.002 \\
(0.032)\end{array}$ \\
\hline$\Delta$ Social goals & $\begin{array}{l}0.013 \\
(0.043)\end{array}$ & $\begin{array}{l}-0.075^{*} \\
(0.045)\end{array}$ \\
\hline$\Delta$ Worries & $\begin{array}{l}-0.111 * * * \\
(0.013)\end{array}$ & $\begin{array}{l}0.119^{* * * *} \\
(0.013)\end{array}$ \\
\hline$\Delta$ Mistrust & $\begin{array}{l}0.019 \\
(0.036)\end{array}$ & $\begin{array}{l}0.006 \\
(0.038)\end{array}$ \\
\hline$\Delta$ Risk & $\begin{array}{l}0.013^{* * * *} \\
(0.004)\end{array}$ & $\begin{array}{l}-0.015^{* * * *} \\
(0.004)\end{array}$ \\
\hline \multicolumn{3}{|l|}{ Personality traits } \\
\hline Neuroticism & $\begin{array}{l}0.012 * * \\
(0.005)\end{array}$ & $\begin{array}{l}-0.006 \\
(0.005)\end{array}$ \\
\hline Extraversion & $\begin{array}{l}-0.001 \\
(0.006)\end{array}$ & $\begin{array}{l}0.001 \\
(0.005)\end{array}$ \\
\hline Openness & $\begin{array}{l}-0.002 \\
(0.006)\end{array}$ & $\begin{array}{l}0.003 \\
(0.005)\end{array}$ \\
\hline Agreeableness & $\begin{array}{l}-0.004 \\
(0.006)\end{array}$ & $\begin{array}{l}0.002 \\
(0.006)\end{array}$ \\
\hline Conscientiousness & $\begin{array}{l}-0.006 \\
(0.005)\end{array}$ & $\begin{array}{l}-0.002 \\
(0.005)\end{array}$ \\
\hline LOC & $\begin{array}{l}0.003 \\
(0.006)\end{array}$ & $\begin{array}{l}-0.005 \\
(0.005)\end{array}$ \\
\hline Rep_pos & $\begin{array}{l}-0.005 \\
(0.005)\end{array}$ & $\begin{array}{l}0.001 \\
(0.005)\end{array}$ \\
\hline Rep_neg & $\begin{array}{l}0.008 \\
(0.005)\end{array}$ & $\begin{array}{l}0.008 \\
(0.005)\end{array}$ \\
\hline
\end{tabular}


Table 3 (continued)

\begin{tabular}{|c|c|c|}
\hline Variables & Positive changes ${ }^{\mathrm{a}}$ & Negative changes $^{\mathrm{b}}$ \\
\hline \multicolumn{3}{|l|}{ Socio-economic characteristics } \\
\hline Male & $\begin{array}{l}-0.006 \\
(0.005)\end{array}$ & $\begin{array}{l}-0.002 \\
(0.005)\end{array}$ \\
\hline East & $\begin{array}{l}-0.003 \\
(0.034)\end{array}$ & $\begin{array}{l}0.060 * \\
(0.035)\end{array}$ \\
\hline Young & $\begin{array}{l}-0.035 \\
(0.024)\end{array}$ & $\begin{array}{l}0.022 \\
(0.023)\end{array}$ \\
\hline Old & $\begin{array}{l}-0.012 \\
(0.013)\end{array}$ & $\begin{array}{l}0.006 \\
(0.013)\end{array}$ \\
\hline Children & $\begin{array}{l}-0.016 \\
(0.011)\end{array}$ & $\begin{array}{l}0.011 \\
(0.011)\end{array}$ \\
\hline One adult & $\begin{array}{l}0.049^{* *} \\
(0.016)\end{array}$ & $\begin{array}{l}0.009 \\
(0.016)\end{array}$ \\
\hline Two adults & $\begin{array}{l}-0.001 \\
(0.010)\end{array}$ & $\begin{array}{l}0.012 \\
(0.011)\end{array}$ \\
\hline Primary & $\begin{array}{l}-0.035 \\
(0.112)\end{array}$ & $\begin{array}{l}-0.057 \\
(0.110)\end{array}$ \\
\hline Secondary & $\begin{array}{l}-0.067 \\
(0.075)\end{array}$ & $\begin{array}{l}-0.050 \\
(0.070)\end{array}$ \\
\hline Good Health & $\begin{array}{l}0.088^{* * * *} \\
(0.009)\end{array}$ & $\begin{array}{l}-0.128^{* * * *} \\
(0.008)\end{array}$ \\
\hline Owner & $\begin{array}{l}-0.031^{* *} \\
(0.015)\end{array}$ & $\begin{array}{l}0.001 \\
(0.015)\end{array}$ \\
\hline Employed & $\begin{array}{l}-0.012 \\
(0.011)\end{array}$ & $\begin{array}{l}-0.006 \\
(0.010)\end{array}$ \\
\hline Chamberlain-Mundlak terms & Yes & Yes \\
\hline Year dummies & Yes & Yes \\
\hline Number of observations & 66,527 & 66,527 \\
\hline
\end{tabular}

Standard errors shown in brackets using clustering. " $\Delta$ " denotes the annual change in the variable. ${ }^{a}$ These coefficients are the marginal effects concerning positive changes in General Satisfaction. ${ }^{\mathrm{b}}$ These coefficients are the marginal effects concerning negative changes in General Satisfaction. ${ }^{*} p<.1, * * p<.05$, $* * * p<.001$

a decline in General Satisfaction. Similarly, people whose income from the previous four years (Adaptation) increases year by year are more likely to report improvements in General Satisfaction. Thus, bearing in mind these findings, increases in household income, social contacts with people other than the family and being willing to take risk and less 
worried about the economy and environment are the main drivers of improving General Satisfaction in the short term.

\section{Conclusions and Discussion}

Within the conceptual framework of 'beyond GDP', public policies should foster the conditions to enable citizens to lead satisfying lives and improve their quality of life. Such conditions would be beneficial both for people and society as a whole, since they contribute to promoting economic growth and social welfare (DiMaria et al., 2019; Oswald et al., 2015; Piekalkiewicz, 2017). For this reason, the study of what actually produces happiness and, more importantly, how to improve happiness is highly relevant for governments and policymakers in designing and assessing public policies, as well as rethinking subsequent development strategies and implementing reforms (O'Donnell et al., 2014; Odermatt \& Stutzer, 2017; Rojas, 2016). Nonetheless, most of the literature has focused on the determinants of happiness from a static (at level) point of view.

The main goal of our study was to analyse how changes in different factors over time are associated with changes in General Satisfaction distinguishing between the long and short term. After reviewing the literature on changes in subjective well-being, we have developed an empirical strategy that has taken into account the advantageous aspects of these investigations and attempted to overcome their main gaps. In what follows, we provide an overview of the main conclusions arising from the study and discuss some public policy implications.

Overall, our long-term analysis of 15 consecutive years reveals that the concepts of social capital, life goals and cultural dimensions have the greatest capacity to predict changes in subjective well-being. Moreover, the analysis of annual changes or short-term analysis in subjective well-being has shown that economic resources have the highest capacity to predict both rises and falls. Next, we focus on the various groups of correlates studied.

Firstly, regarding economic resources, increases in absolute income are also positively correlated with improvements in subjective well-being in the long term, but are partially offset by comparisons with other richer individuals, which leads to feelings of envy. In the short term, increases in family income are associated with both a higher probability of reporting improvements in well-being and a lower probability of reporting decreases in well-being.

These findings are in line with the literature on income aspirations, since both one's own past income (internal comparisons) and the income of one's own reference group (external comparisons) could contribute to the formation of income aspirations (Bartolini \& Sarracino, 2014; Stutzer, 2004; Van Praag \& Ferrer-i-Carbonell, 2008). Within this framework, it is argued that subjective well-being is negatively correlated with income aspirations, especially if those aspirations far outstrip what people receive (Easterlin, 2001; Keller, 2019; Stutzer, 2004). Starting with the internal comparisons, given that people adapt their income aspirations to their current material situation, those who experienced a change in 
their income situation in the short term (year after year) likely had less time to accustom themselves to their new income situation and probably did not tailor their aspirations to their new income situation (Keller, 2019). This may explain why the variable Adaptation (income of the previous four years) contributes to explaining the probability of reporting increases in General Satisfaction only in the short term. In the long term, however, people managed to adapt their income aspirations in accordance with the economic situation in such a way that adaptation is completed. That is, the increase in income itself engenders a corresponding rise in income aspirations, so that subjective well-being does not change as expected (Easterlin, 2001). Regarding the social comparisons, the higher the income level in the reference group, the higher the individual income aspirations and hence the lower the expected subjective well-being (Stutzer, 2004). The results, both in the short and in the long term, go in this direction. People who experience deprivation are more likely to decrease their overall satisfaction from year to year. In the long run, relative deprivation counteracts about half the positive effect of household income on subjective well-being.

Connecting the results of economic resources in our models with the context of the Easterlin paradox, we found that although income matters in the long run, its effect on subjective well-being is reduced by social comparisons. Hence the net effect of income is negligible in the long run. This is compatible with the explanation of the Easterlin paradox. In the short run, Easterlin himself agrees that income is an important correlate of subjective well-being. In sum, economic resources matter for changes in well-being in the short run, but much less so in the long run. This is already well established in the literature and accounted for in the explanation of the Easterlin paradox. In our study, the paradox is not confirmed in the short term or in the long term. Thus, economic resources do matter for changes in subjective well-being.

Secondly, focusing on social capital and more specifically on the concept most correlated with changes in subjective well-being in the long and short term, namely social relationships and networks with individuals other than family and friends (Bridging), it is worth highlighting its behaviour in the long term. Over the period 1999-2014, Bridging registered one of the largest decreases in all the concepts studied. This behaviour, which has slowed down improvements in subjective well-being in Germany in the long term, could be justified by the growing materialism and erosion of social capital that can accompany an economic crisis (Mikucka et al., 2017; Sarracino \& Mikucka, 2019; Sarracino and Piekalkiewicz, 2021).

Several public policy implications can be deduced from these findings. As several studies have argued, policymakers should pay more attention to the effects of future economic policies on the provision and preservation of social capital and promote personal interactions (Bartolini et al., 2019; Odermatt \& Stutzer, 2017; Sarracino, 2010). This can be 
achieved, for instance, by providing meeting places and parks and through other urban planning policies, by supporting the arts and sports and by offering more cultural and social events such as concerts. This kind of policies are also remarkable because they have an indirect positive effect on subjective well-being through decreases in loneliness and possible improvements in mental health, both of which are determinants of changes in subjective well-being (see Becchetti et al., 2018; Bartolini et al., 2019).

Thirdly, as regards life goals and cultural dimensions, the concept that most correlates with changes in subjective well-being in the long and short term are people's concerns about economic development, finances, peace and the environment. Thus, although the own economic situation (income) is less relevant to predict changes in subjective well-being in the long term, economic factors must be taken into account since, as several studies have shown (De Neve et al., 2018; Easterlin, 2021; Macchia \& Oswald, 2021), worries about the country's economic situation and finances are relevant in predicting such changes. Public policies aimed at promoting economic stability and combating climate change contribute to a suitable environment and reduce people's worries, thus improving well-being. Moreover, an appropriate physical environment is associated with social relationships and hence with subjective well-being, since it affects the character and frequency of interactions with others or social capital (O'Donnell et al., 2014).

Finally, the inclusion of personality traits among the determinants of changes in subjective well-being is key, since, as discussed previously, the stability of personality traits and their strong correlation with subjective well-being is one of the foundations of the set-point theory (Diener \& Lucas, 1999). That is, provided that the statistical information allows it, personality traits should be considered at least as control variables in the analysis of changes in subjective well-being over time to achieve more reliable estimates.

To sum up, in line with the conceptual framework developed in several studies (McGilivray, 2007; Stutzer \& Frey, 2010; Stiglitz et al., 2011; OECD, 2013; Bartolini et al., 2014; O'Donnell et al., 2014; Odermatt \& Stutzer, 2017), our results indicate that both the objective circumstances in which people live and the subjective assessment that they make of their lives influence changes in well-being over time.

\section{Appendix}

See Tables 4 and 5 


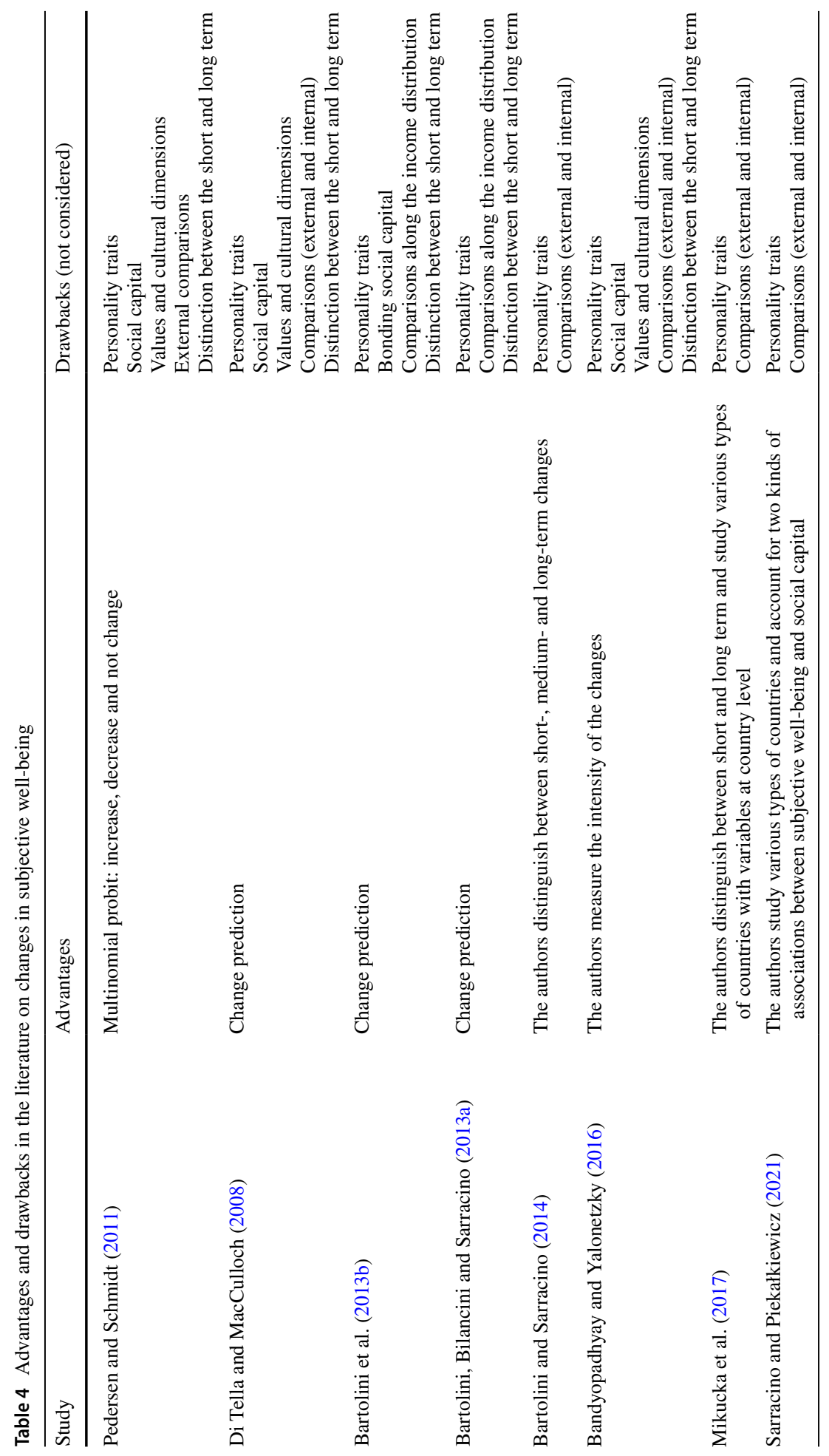


Table 5 POLS estimation of general satisfaction for the period 1999-2014
Variables

Economic Resources

Absolute Income

$1.320 * * *$

(0.272)

Adaptation

0.012

(0.105)

$-0.083^{* * *}$

$(0.014)$

$0.030^{* *}$

(0.015)

Social Capital

Bonding

$0.024 * * *$

$(0.007)$

$0.339 * * *$

(0.026)

Values and Cultural Dimensions

Economic Goals

$-0.029$

$(0.025)$

$0.082 * * *$

$(0.020)$

$0.208^{* * * *}$

(0.029)

$-0.424 * * *$

(0.015)

$-0.232^{* * *}$

(0.023)

$0.026^{* * * *}$

(0.004)

Personality Traits

Neuroticism

$-0.078 * * *$

(0.005)

$0.021^{* * * *}$

(0.005)

$0.014 * *$

(0.005)

$0.037 * * *$

(0.005)

$0.033 * * *$

(0.005)

$-0.063^{* * *}$

(0.005)

$0.018 * * *$

(0.005)

-0.010 **

(0.005) 
Table 5 (continued)

\begin{tabular}{|c|c|}
\hline \multicolumn{2}{|l|}{ Variables } \\
\hline \multicolumn{2}{|c|}{ Socio-Economic Characteristics } \\
\hline Male & $\begin{array}{l}-0.058^{* * *} \\
(0.012)\end{array}$ \\
\hline East & $\begin{array}{l}-0.162^{* * *} \\
(0.015)\end{array}$ \\
\hline Young & $\begin{array}{l}0.099 * * * \\
(0.017)\end{array}$ \\
\hline Old & $\begin{array}{l}0.150 * * * \\
(0.011)\end{array}$ \\
\hline Children & $\begin{array}{l}0.038 * * \\
(0.012)\end{array}$ \\
\hline One adult & $\begin{array}{l}-0.108^{\text {*** }} \\
(0.017)\end{array}$ \\
\hline Two adults & $\begin{array}{l}0.007 \\
(0.010)\end{array}$ \\
\hline Primary & $\begin{array}{l}-0.036 \\
(0.036)\end{array}$ \\
\hline Secondary & $\begin{array}{l}-0.020 \\
(0.024)\end{array}$ \\
\hline Good Health & $\begin{array}{l}0.419 * * * \\
(0.008)\end{array}$ \\
\hline Owner & $\begin{array}{l}0.060 * * * \\
(0.010)\end{array}$ \\
\hline Employed & $\begin{array}{l}0.018 * \\
(0.010)\end{array}$ \\
\hline Constant & $\begin{array}{l}-2.284 * * * \\
(0.236)\end{array}$ \\
\hline Year dummies & Yes \\
\hline Mundlak's correction & Yes \\
\hline Number of observations & 66.527 \\
\hline R-squared (overall) & 0.298 \\
\hline
\end{tabular}

Random effects regression with standard errors shown in brackets using clustering. ${ }^{*} p<.1, * * p<.05, * * * p<.001$

Supplementary Information The online version contains supplementary material available at https://doi. org/10.1007/s10902-021-00473-3.

Acknowledgements The authors gratefully acknowledge the financial support provided by the Government of Spain through grant ECO2015-63734-P (MINECO/FEDER), the FPU2014/1123 fellowship from the Spanish Ministry of Education and the Fortalecimiento Program of the University of Granada (SEJ-340, SEJ-393). Funding for open access charge: Universidad de Granada/ CBUA.

\section{Declarations}

Conflicts of interest The authors declare they have no financial interests neither non financial. 
Ethical approval Authors declare there are not conflicts of interest and this research does not involve human participants or animals. We only use data from the survey SOEP and we have license to use it.

Open Access This article is licensed under a Creative Commons Attribution 4.0 International License, which permits use, sharing, adaptation, distribution and reproduction in any medium or format, as long as you give appropriate credit to the original author(s) and the source, provide a link to the Creative Commons licence, and indicate if changes were made. The images or other third party material in this article are included in the article's Creative Commons licence, unless indicated otherwise in a credit line to the material. If material is not included in the article's Creative Commons licence and your intended use is not permitted by statutory regulation or exceeds the permitted use, you will need to obtain permission directly from the copyright holder. To view a copy of this licence, visit http://creativecommons.org/licenses/by/4.0/.

\section{References}

Bandyopadhyay, S., \& Yalonetzky, G. (2016). An individual-based approach to the measurement of multiple-period mobility for nominal and ordinal variables. CGR Working Paper, 65.

Bárcena-Martín, E., Cortés-Aguilar, A., \& Moro-Egido, A. (2017). Social comparisons on subjective wellbeing: The role of social and cultural capital. Journal of Happiness Studies, 18(4), 1121-1145.

Bartolini, S., Bilancini, E., \& Pugno, M. (2013a). Did the decline in social connections depress Americans' happiness? Social Indicators Research, 110(3), 1033-1059.

Bartolini, S., Bilancini, E., \& Sarracino, F. (2013b). Predicting the trend of Well-Being in Germany: How much do comparisons, adaptation and sociability matter? Social Indicators Research, 114, 169-191.

Bartolini, S., \& Sarracino, F. (2014). Happy for how long? How social capital and economic growth relate to happiness over time? Ecological Economics, 108, 242-256.

Bartolini, S., \& Sarracino, F. (2015). The dark side of Chinese growth: Declining social capital and wellbeing in times of economic boom. World Development, 74, 333-351.

Bartolini, S., Piekalkiewicz, M., \& Sarracino, F. (2019). A Social Cure for Social Comparisons. Quaderni del dipartimento di economía política e statistica, N. 797.

Becchetti, L., Conzo, P., \& Di Febbraro, M. (2018). The monetary-equivalent effect of voluntary work on mental wellbeing in Europe. Kyklos, 71(1), 3-27.

Brdar, I., Majda, R., \& Dubravka, M. (2009). Life goals and well-being: Are extrinsic aspirations always detrimental to well-being? Psihologijske Teme, 18(2), 317-334.

Brockmann, H., Delhey, J., Welzel, C., \& Yuan, H. (2009). The China puzzle: Falling happiness in a rising economy. Journal of Happiness Studies, 10, 387-405.

Budría, S., \& Ferrer-i-Carbonell, A. (2019). Life satisfaction, income comparisons and individual traits. Review of Income and Wealth, 65(2), 337-357. https://doi.org/10.1111/roiw.12353

Chakravarty, S. R. (1997). Relative deprivation and satisfaction orderings. Keio Economic Studies, $34(2), 17-31$.

Chebotareva, E. (2015). Cultural Specifics of Life Values and Subjective Well-Being. Mediterranean Journal of Social Sciences, 6(2 S5), 301-307. https://www.richtmann.org/journal/index.php/mjss/ article/view/6195.

Chica-Olmo, J., Sánchez, A., \& Sepúlveda-Murillo, F. H. (2020). Assessing Colombia’s policy of socioeconomic stratification: An intra-city study of self-reported quality of life. Cities, 97, 102560. https://doi.org/10.1016/j.cities.2019.102560

Clark, A., Frijters, P., \& Shields, M. (2008). Relative income, happiness, and utility: An explanation for the Easterlin paradox and other puzzles. Journal of Economic Literature, 46(1), 95-144.

Conceicao, P., \& Bandura, R. (2008). Measuring Subjective Wellbeing: A Summary Review of the Literature. Office of Development Studies, United Nations Development Programme (UNDP) Research Paper, New York.

D’Ambrosio, C., \& Frick, J. R. (2012). Individual well-being in a dynamic perspective. Economica, 79, 284-302.

De Neve, J. E., Ward, G., De Keulenaer, F., Van Landeghem, B., Kavetsos, G., \& Norton, M. I. (2018). The asymmetric experience of positive and negative economic growth: Global evidence using subjective well-being data. The Review of Economics and Statistics, 100(2), 362-375. https://doi.org/ 10.1162/REST_a_00697 
Diener, E. (2009). Introduction - Culture and Well-Being Works by Ed Diener. In E. Diener (ed.). Culture and Well-being. The collected works of Ed Diener. Springer, Social Indicators Research Series, vol. 38 (pp. 1-8).

Diener, E., \& Lucas, R. E. (1999). Personality and subjective well-being. In D. Kahneman, E. Diener, \& N. Schwarz (Eds.), Well-being: The foundations of hedonic psychology (pp. 213-229). Russell Sage Foundation.

DiMaria, C., Peroni, C., \& Sarracino, F. (2019). Happiness matters: Productivity gains from subjective well-being. Journal of Happiness Studies, 21(1), 139-160.

Di Tella, R., Haisken-De New, J., \& MacCulloch, R. (2010). Happiness adaptation to income and to status in an individual panel. Journal of Economic Behavior \& Organization, 76(3), 834-852.

Di Tella, R., \& MacCulloch, R. (2008). Gross national happiness as an answer to the Easterlin Paradox? Journal of Development Economics, 86, 22-42.

Dohmen, T., Falk, A., Huffman, D., Sunde, U., Schupp, J., \& Wagner, G. G. (2011). Individual risk attitudes: Measurement, determinants and behavioral consequences. Journal of the European Economic Association, 9(3), 522-550.

Dolan, P., \& Metcalfe, R. (2012). Measuring subjective well-being: Recommendations on measures for use by national governments. Journal of Social Policy, 41(2), 409-427.

Easterlin, R. (1974). Does Economic Growth Improve the Human Lot? Some Empirical Evidence. In R. David \& M. Reder (Eds.), Nations and households in economic growth (pp. 89-125). Academic Press.

Easterlin, R. A. (2001). Income and happiness: Towards a unified theory. The Economic Journal, 111, 465-484.

Easterlin, R. A. (2021). Why Does Happiness Respond Differently to an Increase vs. Decrease in Income?. IZA Discussion Paper No. 14645. https://ssrn.com/abstract=3908860

Ferrer-i-Carbonell, A. (2005). Income and well-being: An empirical analysis of the comparison income effect. Journal of Public Economics, 89, 997-1019.

Ferrer-i-Carbonell, A., \& Frijters, P. (2004). How important is methodology for the estimates of the determinants of happiness? The Economic Journal, 114, 641-659.

Ferrer-i-Carbonell, A., \& Ramos, X. (2014). Inequality and happiness. Journal of Economic Surveys, 28(5), 1016-1027.

Frederick, S., \& Loewenstein, G. (1999). Hedonic adaptation. In D. Kahneman, E. Diener, \& N. Schwarz (Eds.), Well-being: The foundations of hedonic psychology (pp. 302-329). Russell Sage Foundation.

Frey, B., \& Stutzer, A. (2002). What can economists learn from happiness research? Journal of Economic Literature, 40(2), 402-435.

Frey, B., \& Stutzer, A. (2017). Public Choice and Happiness. Center for Research in Economics, Management and the Arts (CREMA), 2017-03.

Gelati, D., Manzano, M., \& Sotgiu, I. (2006). The subjective components of happiness and their attainment: A cross-cultural comparison between Italy and Cuba. Social Science Information, 45(4), 601-630. https://doi.org/10.1177/0539018406069594

Headey, B., \& Muffels, R. (2018). A theory of life satisfaction dynamics: Stability, change and volatility in 25-year life trajectories in Germany. Social Indicators Research, 140(2), 837-866.

Helliwell, J., \& Putnam, R. (2004). The social context of well-being. Philosophical Transactions of the Royal Society, 359(1449), 1435-1446.

Hey, J. D., \& Lambert, P. (1980). Relative deprivation and gini coefficient: Comment. The Quarterly Journal of Economics, 95(3), 567-573.

Keller, T. (2019). Caught in the monkey trap: Elaborating the hypothesis for why income aspiration decreases life satisfaction. Journal of Happiness Studies, 20, 829-840. https://doi.org/10.1007/ s10902-018-9969-z

Kristoffersen, I. (2018). Great expectations: Education and subjective wellbeing. Journal of Economic Psychology, 66, 64-78.

Lareau, A., \& Weininger, E. B. (2003). Cultural capital in educational research: A critical assessment. Theory and Society, 32, 567-606.

Layard, R., Mayraz, G., \& Nickell, S. (2009). Does relative income matter? Are the critics right? SOEPPaper, 210.

Lucas, R., \& Brent, M. (2007). How stable is happiness? Using the STARTS model to estimate the stability of life satisfaction. Journal of Research in Personality, 41(5), 1091-1098.

Macchia, L., \& Oswald, A. J. (2021). Physical pain, gender, and the state of the economy in 146 nations. Social Science \& Medicine, 287, 114332. https://doi.org/10.1016/j.socscimed.2021.114332

Maggino, F., \& Facioni, C. (2017). Measuring stability and change: Methodological issues in quality of life studies. Social Indicators Research, 130, 161-187. 
McGillivray, M. (2007). Human well-being: Issues, concepts and measures. In M. McGilivray (Ed.), Human well-being: Concept and measurement (pp. 1-22). Londres: Palgrave MacMillian.

Mikucka, M., Sarracino, F., \& Dubrow, J. K. (2017). When does economic growth improve life satisfaction? Multilevel analysis of the roles of social trust and income inequality in 46 countries, 19812012. World Development, 93, 447-459. https://doi.org/10.1016/j.worlddev.2017.01.002

Muffels, R., \& Headey, B. (2013). Capabilities and choices: Do they make Sen`se for understanding objective and Subjective Well-Being? An empirical test of sen's capability framework on german and british panel data. Social Indicators Research, 110, 1159-1185.

Mundlak, Y. (1978). On the pooling of time series and cross section data. Econometrica, 46, 89-85.

Navarro, M., \& Sánchez, A. (2018). Ingreso y Bienestar Subjetivo: el Efecto de las Comparaciones Sociales. Revista de Economía Mundial, 48, 139-156. http://hdl.handle.net/10272/14722

Neira, I., Bruna, F., Portela, M., \& García-Aracil, A. (2018). Individual well-being, geographical heterogeneity and social capital. Journal of Happiness Studies, 19(4), 1067-1090.

O’Donnell, G., Deaton, A., Durand, M., Halpern, D., \& Layard, R. (2014). Wellbeing and policy (Report). Commissioned by the Legatum Institute.

Odermatt, R., \& Stutzer, A. (2017). Subjective Well-Being and Public Policy. IZA Discussion Paper N. 11102.

OECD (2013). How's life? 2013. Measuring well-being. OECD publishing.

Oishi, S., \& Diener, E. (2009). Goals, Culture, and Subjective Well-Being. In E. Diener (Ed.), Culture and Well-being. The collected works of Ed Diener. Springer, Social Indicators Research Series (vol. 38, pp. 93-108).

Oswald, A. J., Proto, E., \& Sgroi, D. (2015). Happiness and productivity. Journal of Labor Economics, 33(4), 789-822.

Pedersen, P. J., \& Schmidt, T. D. (2011). Happiness in Europe: Cross-country differences in the determinants of satisfaction with main activity. The Journal of Socio-Economics, 40(5), 480-489.

Peters, W. S., \& Butler, J. Q. (1970). The construction of regional economic indicators by principal components. Annals of Regional Science, 4, 1-4.

Piekalkiewicz, M. (2017). Why do economists study happiness? The Economic and Labour Relations Review, 28(3), 361-377.

Riedl, M., \& Geishecker, I. (2014). Keep it simple: estimation strategies for ordered response models with fixed effects. Journal of Applied Statistics, 41(11), 2358-2374.

Rojas, M. (2016). The Relevance of Happiness: Choosing Between Development Paths in Latin America. In M. Rojas (Ed.), Handbook of Happiness Research in Latin America (pp. 51-62). Springer. DOI https://doi.org/10.1007/978-94-017-7203-7_1

Rözer, J., \& Kraaykamp, G. (2013). Income inequality and subjective well-being: A cross-national study on the conditional effects of individual and national characteristics. Social Indicators Research, 113, 1009-1023. https://doi.org/10.1007/s11205-012-0124-7

Sabatini, F. (2009). Social capital as social networks: A new framework for measurement and an empirical analysis of its determinants and consequences. The Journal of Socio-Economics, 38, 429-442.

Sarracino, F. (2010). Social capital and subjective well-being trends: Comparing 11 western European countries. The Journal of Socio-Economics, 39, 482-517.

Sarracino, F., \& Mikucka, M. (2019). Consume more, work longer, and be unhappy: Possible social roots of economic crisis? Applied Research in Quality of Life, 14, 59-84. https://doi.org/10.1007/ s11482-017-9581-0

Sarracino, F., \& Piekałkiewicz, M. (2021). The role of income and social capital for europeans' well-being during the 2008 economic crisis. Journal of Happiness Studies, 22, 1583-1610. https://doi.org/10. 1007/s 10902-020-00285-X

Schimmack, U., Radhakrishnan, P., Oishi, S., Dzokoto, V., \& Ahadi, V. (2002). Culture, personality, and subjective well-being: Integrating process models of life satisfaction. Journal of Personality and Social Psychology, 82(4), 582-593.

Schwartz, S. H. (2017). The refined theory of basic values. In S. Roccas \& L. Sagiv (Eds.), Values and behavior: Taking a cross-cultural perspective (pp. 51-72). Springer International Publishing.

Schwartz, S. H., Sagiv, L., \& Boehnke, K. (2000). Worries and values. Journal of Personality, 68, 309-346.

Schwartz, S. H., \& Sortheix, F. M. (2018). Values and subjective well-being. In E. Diener, S. Oishi, \& L. Tay (Eds.). Handbook of well-being. Salt Lake City, UT: DEF Publishers.

Schwarze, J., \& Härpfer, M. (2007). Are people inequality averse, and do they prefer redistribution by the state? Evidence from German longitudinal data on life satisfaction. The Journal of Socio-Economics, $36,233-249$.

Stiglitz, J., Sen, A., \& Fitoussi, J. (2011). Mismeasuring Our Lives: Why GDP doesn't Add Up. The New Press. 
Stutzer, A. (2004). The role of income aspirations in individual happiness. Journal of Economic Behavior \& Organization, 54(1), 89-109.

Stutzer, A., \& Frey, S. (2010). Recent advances in the economics of individual subjective well-being. Social Research, 77(2), 679-714.

Tsui, H. (2014). What affects happiness: Absolute income, relative income or expected income? Journal of Policy Modeling, 36(6), 994-1007.

Tsurumi, T., Imauji, A., \& Managi, S. (2019). Relative income, community attachment and subjective wellbeing: Evidence from Japan. Kyklos, 1, 152-182.

Van Praag, B.M.S., \& Ferrer-i-Carbonell, A. (2008). Happiness Quantified: A satisfaction calculus approach. Oxford University Press. Revised edition.

Veenhoven, R. (2017). Greater happiness for a greater number: Did the promise of enlightenment come True? Social Indicators Research, 130, 9-25.

Wolfers, J., Sacks, D., \& Stevenson, B. (2012). The new stylized facts about income and subjective wellbeing. Emotion, 12(6), 1181-1187.

Woolcock, M., \& Narayan, D. (2000). Social capital: Implications for development theory, research, and policy. The World Bank Research Observer, 15(2), 225-249.

Yap, S., Anusic, I., \& Lucas, R.E. (2014). Does Happiness Change? Evidence from Longitudinal Studies. In K.M. Sheldon, and R.E. Lucas (Eds.), Stability of Happiness. Theories and Evidence on Whether Happiness Can Change (pp. 127-145). Elsevier. https://doi.org/10.1016/B978-0-12-411478-4.00007-2

Yitzhaki, S. (1979). Relative deprivation and the gini coefficient. The Quarterly Journal of Economics, 93(2), 321-324.

Publisher's Note Springer Nature remains neutral with regard to jurisdictional claims in published maps and institutional affiliations. 